Adrian F. Fernando, MD Antonio H. Chua, MD

Department of Otorhinolaryngology Head and Neck Surgery University of the East - Ramon Magsaysay Memorial Medical Center
Correspondence: Adrian F. Fernando, MD

Department of Otorhinolaryngology Head and Neck Surgery, University of the East - Ramon Magsaysay

Memorial Medical Center,

Aurora Blvd., Quezon City 1114

Philippines

Telefax: (632) 7161789

E-mail: ianfernando_md@yahoo.com

Reprints will not be available from the authors.

No funding support was received for this study. The authors signed a disclosure that they have no proprietary or financial interest with any organization that may have a direct interest in the subject matter of this manuscript, or in any product cited in this report.

\section{Dysphagia as the Initial Presenting Symptom of Amyotrophic Lateral Sclerosis}

\author{
ABSTRACT \\ Objective: To present a case of Amyotrophic Lateral Sclerosis (ALS) with an unusual initial \\ presentation of dysphagia. \\ Methods: \\ Design: Case report \\ Setting: Private tertiary university hospital \\ Patient: One
}

Results: A 78-year-old female with two years' progressive dysphagia thrice refused biopsy of a right oropharyngeal bulge recommended by three different otorhinolaryngologists. Slurring developed, but normal cranial CT scans cleared her of a cerebrovascular event. Subsequent marked weight loss, dysarthria and lower extremity weakness led to tests including an electromyogram and nerve conduction velocity study (EMG-NCV) consistent with amyotrophic lateral sclerosis (ALS).

Conclusion: Awareness of neurologic disorders that cause dysphagia may prevent unnecessary diagnostic interventions. Algorithms for evaluation and management of dysphagia may also reduce misdiagnosis and consequent mismanagement. ALS may be considered whenever symptoms of dysphagia present with subsequent development of other motor neurologic signs of denervation such as fasciculation, weakness and atrophy. Otorhinolaryngologists play a vital role in the ALS team in light of the need for thorough swallowing evaluation and airway support.

Key words: dysphagia, Amyotrophic Lateral Sclerosis (ALS), bulbar-onset ALS, oropharyngeal mass

Dysphagia is the perception of an impediment to the normal passage of swallowed material which can occur anywhere from the oral cavity to the esophagus. ${ }^{1}$ Evaluation of dysphagia must first focus on the basic physiology of swallowing, as an accurate assessment of the type of dysphagia (oropharyngeal vs. esophageal) can be made with careful history alone in about $80-85 \%$ of cases. $^{2}$ 
This case describes how amyotrophic lateral sclerosis or ALS can initially present with dysphagia and how its associated physical manifestations can be mistaken for an oropharyngeal malignancy. The standard approach to dysphagia evaluation and management as well as the role of otorhinolaryngologists in ALS management will be discussed.

\section{CASE REPORT}

A 78-year-old diabetic female was referred to our out-patient clinic for progressive dysphagia of two years. She initially had difficulty initiating swallowing solids, leading to coughing, choking and occasional nasal regurgitation. A year after, her endocrinologist noted slurring of speech and persistence of dysphagia. A cerebrovascular event was ruled out by a neurologist following a cranial CT-scan and she was referred to an otorhinolaryngologist. Videolaryngoscopy revealed right oropharyngeal wall bulging with narrowing of the oropharynx. She refused the recommended biopsy and eventually consulted another otorhinolaryngologist whose recommended biopsy she also refused.

Five months later, she had marked weight loss and generalized body weakness. CT scans revealed soft tissue fullness of the right oropharynx contiguous with the tongue base, vallecula and prevertebral soft tissue interpreted as a right oropharyngeal mass. She again refused the recommended biopsy.

She consulted us wheel-chair bound, with marked body weakness and dysarthria. Oropharyngeal examination (Figure 1) revealed a smooth, non-tender right bulge with same consistency as adjacent oropharyngeal structures causing marked narrowing of the oropharyngeal area. Videolaryngoscopy (Figure 2) also revealed bilateral mobile vocal folds with no glottic lesion or aspiration. Her tongue slightly deviated to the left, with weak protrusion and fasciculations. Her gag reflex was normal, her uvula midline and the rest of the cranial nerve examination was unremarkable. There was left lower extremity atrophy with grade $3 / 4$ motor strength. She had no sensory deficits. The cerebellar exam was also normal. The previous neck CT-scan (Figure 3) was reviewed and again interpreted as a right oropharyngeal mass, but instead of recommending a biopsy, we requested Electromyography and Nerve Conduction Velocity (EMG-NCV) tests and results suggested a purely motor neuron denervation disease consistent with amyotrophic lateral sclerosis or ALS. After appropriate disclosure and counseling, an elective tracheotomy and percutaneous gastrostomy (PEG) were performed.

After 5 months, she has gained weight and markedly improved nutritional status. However, oropharyngeal narrowing (Figure 4) has increased, tongue fasciculations and atrophy are more prominent and drooling is evident. Quarterly follow-up consultations at the otorhinolaryngology, neurology and medicine out-patient clinics have been scheduled.

\section{DISCUSSION}

A large number of adults beyond the $5^{\text {th }}$ decade of life and approximately $25 \%$ of hospitalized patients experience dysphagia. ${ }^{3}$ It can be caused by numerous etiologies (Figure 5) generally localized

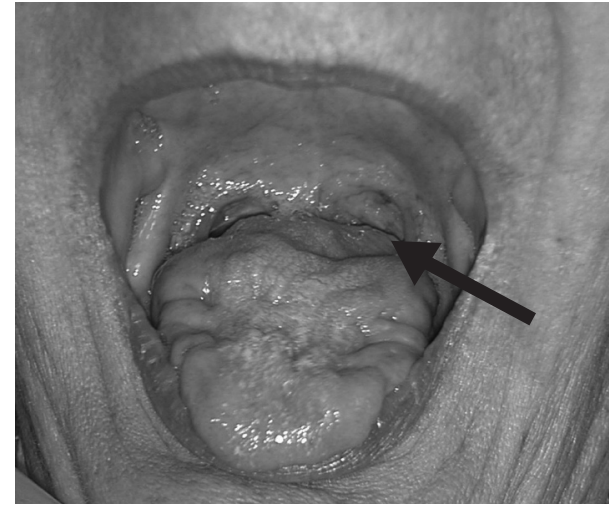

Figure 1. Tongue atrophy, with normal gag, presence of tongue fasciculation, and narrowing of the oropharyngeal area. Uvula still visualized. (Arrow)

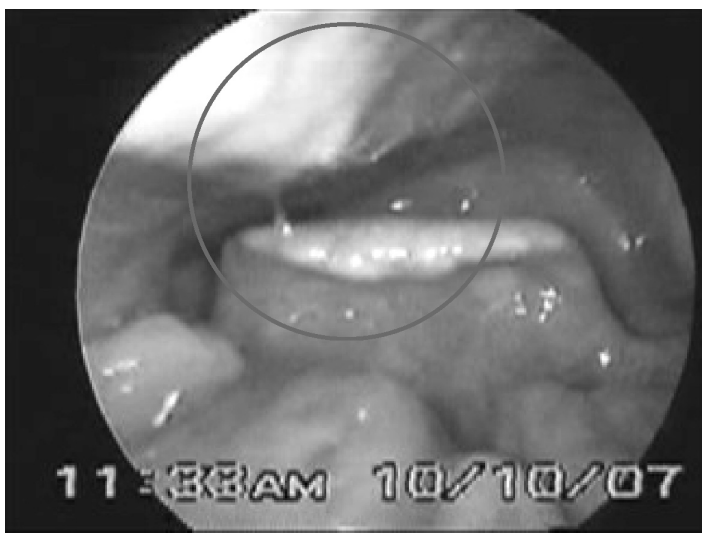

Figure 2. Video laryngoscopy at time of admission showing a bulge at the right posterolateral oropharyngeal wall and narrowing of the oropharygeal area.

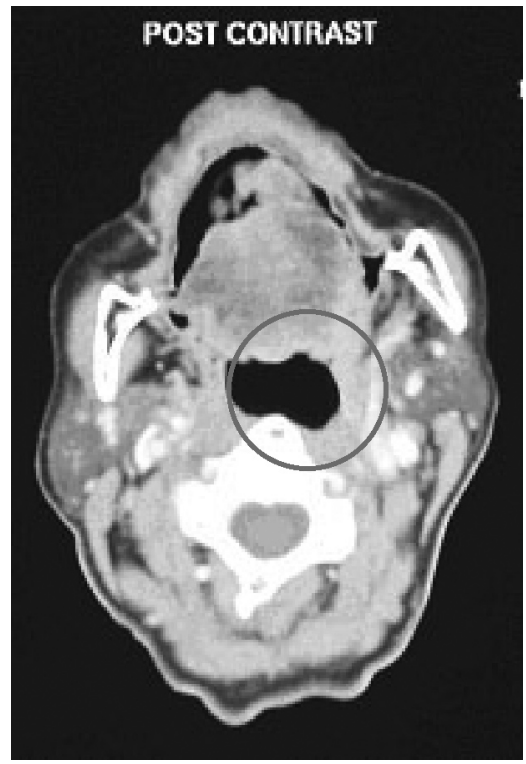

Figure 3. Post contrast neck CT scan, dated July 5, 2007 showing narrowing of the oropharyngeal area due to the presence of a non-enhancing oropharyngeal bulge at the right posterolateral oropharyngeal wall extending to the base of the tongue contiguous with the prevertebral soft tissues. 


\section{CASE REPORTS}

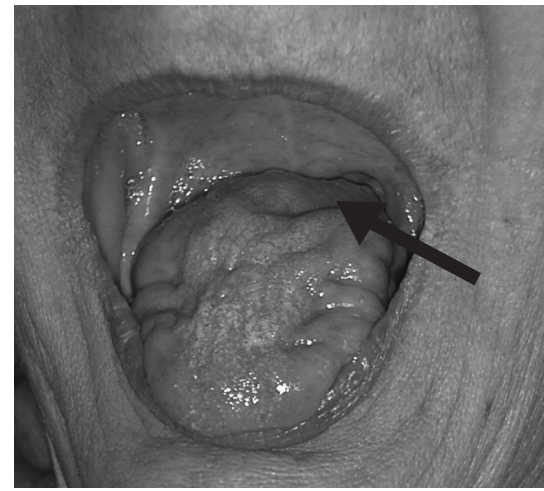

Figure 4. Noted is the persistent narrowing of the oropharyngeal area (Arrow), and the tongue atrophy. Tongue fasciculations were grossly appreciated.

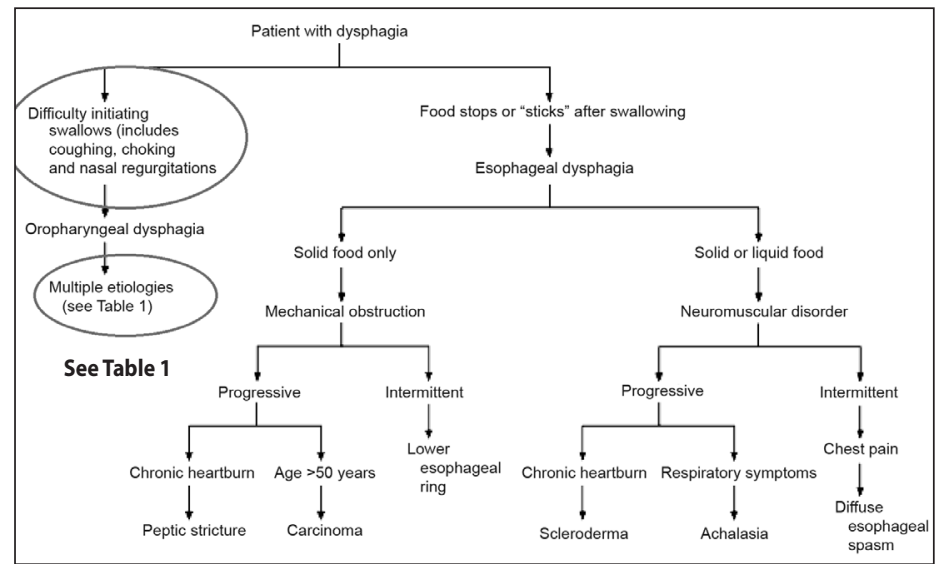

Figure 5. Differentiating symptoms of dysphagia. Information from Castell DO. Approach to the patient with dysphagia. In: Yamada T, ed. Textbook of gastroenterology. 2d ed. Philadelphia: Lippincott Williams \& Wilkins, 1995.

Table 1. Information from Castell DO, Donner MW. Evaluation of Dysphagia: A Careful History is Crucial. Dysphagia 1987; 2:65-71.

\begin{tabular}{|c|c|c|}
\hline \multicolumn{3}{|c|}{ Selected Causes of Oral and Pharyngeal Dysphagia } \\
\hline Neurologic disorders and stroke: & Structural lesions: & Psychiatric disorder: \\
\hline $\begin{array}{l}\text { Cerebral infarction } \\
\text { Peripheral neuropathy Brain-stem } \\
\text { infarction } \\
\text { Intracranial hemorrhage } \\
\text { Parkinson's disease } \\
\text { Multiple sclerosis } \\
\text { Amyotrophic lateral sclerosis } \\
\text { Poliomyelitis Dermatomyositis } \\
\text { Postinfectious } \\
\text { Myasthenia gravis } \\
\text { Dementias }\end{array}$ & $\begin{array}{l}\text { Thyromegaly } \\
\text { Cervical hyperostosis } \\
\text { Congenital web } \\
\text { Zenker's diverticulum } \\
\text { Ingestion of caustic material } \\
\text { Inflammatory mass } \\
\text { Neoplasm }\end{array}$ & $\begin{array}{l}\text { Psychogenic dysphagia } \\
\text { Connective tissue } \\
\text { diseases: } \\
\text { Polymyositis } \\
\text { Muscular dystrophy } \\
\text { latrogenic causes: } \\
\text { Surgical resection } \\
\text { Radiation fibrosis } \\
\text { Medications }\end{array}$ \\
\hline
\end{tabular}

in the oropharynx or esophagus. ${ }^{4}$ Neurologic causes should always be considered in the absence of signs of obstruction along the upper gastrointestinal tract (Table 1). Motor neuron disorder (MND) is a possible neurologic cause of dysphagia after the exclusion of stroke as $80 \%$ of all MND patients develop bulbar problems. Among the different conditions under MND, ALS is known to cause both upper and lower motor neuron affectations.

ALS was first described in 1869 by the French neurologist JeanMartin Charcot and is called Charcot's Disease in Europe. It is also known as Lou Gehrig's Disease in the United States, after the famous baseball player who died of pulmonary complications a few years after he was diagnosed with ALS. ${ }^{5} \mathrm{ALS}$ is a fatal neurodegenerative disease occurring in 5 out of 100,000 . The male to female ratio is approximately 1.6:1 and the average age of onset is in the fourth to seventh decades of life. The hallmark signs of ALS are progressive weakness of the extremities with later development of muscle cramps, fatigue, twitching and atrophy evident in the arms, shoulders and tongue. A variant called bulbaronset ALS occurs in 25\% MND cases and only 6 to $10 \%$ of reported ALS cases causing primary affectation of the muscles of mastication, the pharynx, the tongue or the face. ${ }^{6}$ While familial, juvenile-onset ALS patients have been reported to survive for longer periods of about 2 to 3 decades, bulbar-onset ALS has a more rapid progression. Average 5 -year-life expectancy is 50 to $60 \%$ and only $20 \%$ survive longer than 5 years. ${ }^{7}$

Understanding the physiology of swallowing is the primary tool in the localization of dysphagia and an algorithm (Figure 6) can serve as a useful guide in its diagnosis and management, reducing the chances of misdiagnosis and consequent mismanagement.

The role of otorhinolaryngologists in ALS encompasses evaluation and supportive care. It becomes more critical in cases of bulbar-onset ALS where thorough swallowing evaluation and airway management are primary concerns. ${ }^{8}$ Careful history remains the most important localizing tool aided by videolaryngoscopy, functional endoscopic evaluation of swallowing (FEES) and/or barium swallow. Radiographic studies like CT scans and MRI help in exclusion of other diseases. The "oropharyngeal mass" on CT scans of our patient was a non-enhancing soft tissue fullness contiguous and with the same tissue density as adjacent oropharyngeal structures. Absence of a definite delineating border further made an actual mass unlikely. It is plausible that the oropharyngeal bulge was simply caused by sagging of weakened orpharyngeal constrictor muscles.

EMG-NCV is still the key test in the evaluation of nerve and muscle function that shows the pathognomonic denervation exhibited by ALS. ${ }^{9}$ Once a diagnosis of ALS is established, family counselling should be conducted to explain its nature and course, with a discussion of management options. As in our case, PEG tube insertion provides a permanent route for nutrition while elective tracheotomy prevents further airway compromise since respiratory failure is the leading cause of death among patients with MND. ${ }^{10,11}$ Recurrent pulmonary infection is the leading cause of morbidity among ALS patients and nearly all ALS patients die of respiratory failure within 2 to 5 years after the onset of the disease. ${ }^{12}$ 


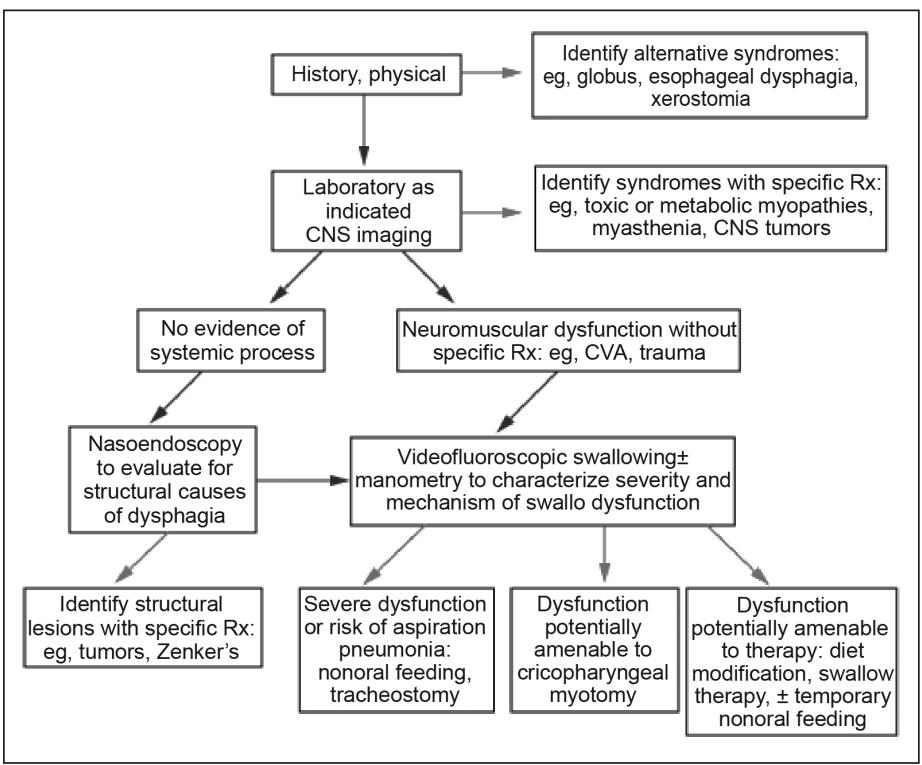

Figure 6. Summary of the Clinical Approach and Key Objectives in the Management of Oropharyngeal Dysphagia. Information from the World Gastroenterology Organisation (WGO) Practice Guidelines on Dysphagia. 2007. Adapted from: Cook, IJ, Kahrilas, PJ. AGA: Technical review: Management of oropharyngeal dysphagia. Gastroenterology 1999; 116:455.

Note: The objective is to reach a box targeted by terminal arrow which equates to a specific management strategy. The arrows indicate a suggested pathway to proceed with the evaluation.

CNS: central nervous system; Rx: therapy; CVA: cerebrovascular accident.

The progressive, disabling nature of ALS and the absence of cure make it difficult to manage. Diverse clinical presentations of various diseases causing dysphagia should always be considered..$^{13}$ Bulbaronset ALS can cause dysphagia as the sole initial symptom prior to the onset of other neurologic signs necessitating careful and immediate ENT evaluation. A team-approach is important in the evaluation and management of dysphagia and ALS, involving specialists in neurology, gastroenterology, pulmonology, otorhinolaryngology, speech/ swallowing therapy and nursing. Considering that 6 out of the 14 most frequent ALS symptoms (Table 2) excluding late-onset dysphagia in classic ALS are all ENT-related symptoms, otorhinolaryngologists are a vital part of the ALS team. ${ }^{14}$

\section{REFERENCES}

1. Malagelada JR, Bazzoli F, Elewaut A, Fried M, Krabshuis JH, Lindberg H, et al. Dysphagia: World Gastroenterology Organisation Practice Guidelines. World Gastroenterology Organization 2007:1

2. Spieker M. Evaluating dysphagia. Am Fam Physician. 2000, Jun 15; 61 (12):2.

3. Layne KA, Losinski DS, Zenner PM, Ament JA. Using the Fleming Index of Dysphagia to Establish Prevalence. J Am Diet Assoc. 1989; (4):39.

4. Brin MF, Younger D. Neurologic disorders and aspiration. Otolaryngol Clin N Am. 1988; 21:6919.

5. Logroscino G, Armon C. Amyotrophic Lateral Sclerosis: A global threat with a possible difference in risk across ethnicities. Am Acad Neuro. 2007; 17:68.

6. Johnson J. Practical management strategies for dysphagia in motor neuron disease and amyotrophic lateral sclerosis. Clinical Speech and Language Therapy Lecture Series. Kings College Hospital. 2007:16.

7. Kutzke JF: Epidemiology of amyotrophic lateral sclerosis. Advanced Neurology. 1982; 36: 281.

8. Logemann J. Mechanism of normal and abnormal swallowing. Otolaryngology - Head and Neck Surgery. $4^{\text {th }}$ ed. Cummings CW, PA: Elsevier Mosby. 2005; (2):1437-45.

9. Talbot K, Ansorge O. Recent advances in the genetics of amyotrophic lateral sclerosis and frontotemporal dementia: Common pathways in neurodegenerative disease. Human Molecular Genetics. 2006; 15(2):2-9.

10. Smith PF. Practical problems in the respiratory care of patients with muscular dystrophy. New Engl J Med. 1987; 316:1197-1205.

11. Braverman J. Airway clearance needs in neuromuscular disease: An overview. Hill-Rom. 2006; $1: 2$.

12. Lechtzin N. Respiratory effects of amyotrophic lateral sclerosis: Problems and solutions. Respir Care J. 2006 Aug; (8):51

13. Ertekin C, Aydogdu I, Yüceyar N, Kiylioglu N, Tarlaci S, Uludag B. Pathophysiological Mechanisms of oropharyngeal dysphagia in amyotrophic lateral sclerosis. Brain $2000 \mathrm{Jan} ; 123$ (1):125-40.

14. Reichenberger E. Understanding ALS. ALS Hope Foundation. 2008 Mar. Available from: http:// www.alshopefoundation.org 